\title{
Developing "the Wings to Really Fly": The Experiences of Four Postdoctoral Research Fellows within an Australian University Faculty of Education
}

\author{
Tuija A. Turunen, ${ }^{1}$ Sandie Wong, ${ }^{2}$ Laurette Bristol, ${ }^{3}$ and Siew Yin $\mathrm{Ho}^{4}$ \\ ${ }^{1}$ Faculty of Education, University of Lapland, P.O. Box 122, 96101 Rovaniemi, Finland \\ ${ }^{2}$ Research Institute for Professional Practice, Learning \& Education, School of Teacher Education, Charles Sturt University, \\ Panorama Avenue, Bathurst, NSW 2795, Australia \\ ${ }^{3}$ Research Institute for Professional Practice, Learning \& Education, Research House, Charles Sturt University, Locked Bag 588, \\ Wagga Wagga, NSW 2678, Australia \\ ${ }^{4}$ Faculty of Education, Science, Technology and Mathematics, University of Canberra, Canberra, ACT 2601, Australia
}

Correspondence should be addressed to Tuija A. Turunen; tuija.turunen@ulapland.fi

Received 30 May 2014; Revised 22 July 2014; Accepted 18 August 2014; Published 31 August 2014

Academic Editor: Jo Lunn Brownlee

Copyright ( 2014 Tuija A. Turunen et al. This is an open access article distributed under the Creative Commons Attribution License, which permits unrestricted use, distribution, and reproduction in any medium, provided the original work is properly cited.

\begin{abstract}
Postdoctoral research fellowships are a recent phenomenon in teacher education and little has been documented about them. This paper presents findings from a study in which the experiences of research fellows in a rural university were investigated. The data were gathered as audio recordings from peer mentoring meetings, notes from these meetings, individual reflective journals, and interviews conducted with six key informants. The analysis highlights that the experience of research fellowships was marked by a need to negotiate four competing, though not necessarily exclusive, demands related to the institute's research productivity, its research culture and teaching, and personal professional goals. A range of institutional practices and individual characteristics mediated these negotiations.
\end{abstract}

\section{Introduction}

Within a larger context of new public managerialism and increased casualisation of the workforce, there are increasing accountability demands placed on universities, usually measured in terms of research output and income [1]. For example, in Sweden and Finland along with other countries, new public funding tools tend to measure research excellence in a quantitative manner $[2,3]$. At the same time, in Australia, the context of the present study, there is a predicted loss of experienced academics due to demographic reasons [4]. These contextual factors result in a need for universities to retain and sustain their existing academics, increase their research productivity, and recruit the next wave of research leaders [5].

One strategy to meet these current demands, employed by a Research Institute within a regional Australian university, was the recruitment of four, three-year term, early career postdoctoral research fellows (hereafter referred to as research fellows, the authors of this paper) located within a Teacher Education community at the Faculty of Education. This paper presents findings from a study in which the activity of being postdoctoral research fellows was investigated using Cultural Historical Activity Theory (CHAT) as a tool for analysis.

\section{Literature Review}

Much of the research to date on postdoctoral research fellowships (PDRF) has been in the natural sciences where they have been common since the 1970s. This research reveals a general lack of consistency in the definition of the PDRF, great variation in how it is conceived, and differences in the title by which fellows are known [6]. Despite these differences, typically, research fellows require or must be close to 
completion of a PhD. PDRFs are usually temporary positions, often limited to early career researchers (ECRs) within the first five years post-Ph.D., which contain a substantive degree of research or scholarship, providing the research fellow with time, freedom, and support for publication, including supervision by a senior scholar [6].

The limited but growing body of literature has tended to concentrate on the general demographics of research fellows, their employment opportunities, and training (e.g., [6-8]). This literature also identifies benefits of the PDRF, at both the individual and organizational levels $[6,9,10]$. At the individual level research fellowships can provide a valuable opportunity to support ECRs to engage in sustained research and gain additional research skills and are often viewed as a stepping-stone into academia $[6,10]$. In particular, increased opportunity to publish and attract external funding contributes to the development of research fellows' profiles, building their academic identities, establishing their place in the academic world, and potentially fast-tracking their career [6]. Moreover, if the research fellowship position is outside their home country it can support research fellows' integration into international networks [11].

Research fellowships also have benefits at the organisational level. With greater casualisation of the workforce and scarcity of tenured teaching positions in universities, PDRFs can be a way of retaining recently graduated $\mathrm{PhDs}$ - who then contribute to the university's research output and targets [6] and the intellectual life of their institutes, potentially strengthening a research intensive ethos within faculties of education by making research activities visible. This is especially important in teacher education, where research is seen as one of the key factors for quality education [12].

In spite of the benefits, there are some challenges. Research fellows can be poorly paid, and PDRF's temporary and insecure nature can place stress on them. Further, with few tenured academic positions available, not all research fellows gain ongoing employment [13] given their limited teaching experience. So research fellows' expectations of a research career can come into conflict with the reality of the academic world, where the PDRF can operate as a kind of "limbo" with many research fellows continuing in ongoing contract research positions or turning to other sectors like applied research or to administrative positions $[6,10]$. Therefore, as Rybarczyk et al. [8] suggest, there is a growing need to prepare research fellows for other than research responsibilities in an academic career such as teaching, contributions to departmental service, and administration.

Other challenges, especially in a teacher education context, are related to the relatively short history of education faculties within universities [14]. Whilst the Ph.D. degree provides a valuable experience in conducting independent research, continuing with research after the doctorate is not easy [15], particularly for those in teaching intensive faculties. Teacher educators often come from teaching backgrounds and their recruitment has been based on their teaching qualifications rather than research achievements [16]. Although research has become an increasingly important part of the teacher educators' work in recent years, research and teaching seem often to belong to different worlds in the teacher education context $[16,17]$, in which PDRFs need to negotiate their practice.

The literature also highlights some contradictions in the PDRFs. For instance, whilst supervisors are generally acknowledged as playing a crucial role, their role often lacks clarity and the degree to which they support research fellows varies [10]. Likewise, collaborative relationships in the form of peer mentoring have been reported as potentially beneficial for ECRs [18]. However, research fellows report that they find it hard to find their peer research fellows and establish relationships with them because it can be difficult to identify them from other staff [6]. Further, whilst academic publishing is widely considered by both research fellows and their supervisors as a critical aspect of the PDRF, there is often uncertainty about what publications and other outputs are expected during the fellowship [6].

As previously noted, in the fields of education and other social sciences, including teacher education, PDRFs are quite a recent phenomenon [10, 19]. Consequently, little is known about the experiences of research fellows in teacher education, where their role may differ from those within natural sciences. Among the few studies of research fellows in social sciences is Åkerlind's $[6,10]$ research examining differences between research fellows in different faculties. Her results indicate that, as with other research fellows, research fellows in social sciences consider the PDRF to be an opportunity for undertaking full-time research. However, in keeping with the tradition of their field, research fellows in social sciences more often concentrate on their individual research and writing than those in the natural sciences.

Åkerlind [10] argues that the limited research pertaining to PDRFs leads to assumptions and stereotypes, which dominate discussions among scholars, and she argues for more research to dispel these myths. In this paper we take up the challenge of contributing to the field of research on early career research fellows by examining our experiences as four research fellows located within a faculty of education in an Australian university.

\section{Context of the Study}

The university in which our PDRFs were located is one of the largest rural universities in Australia, spanning six different campuses across New South Wales. It attracts major funding and research interest in the areas of Agriculture and Veterinary Science, but is also gradually building a rigorous national and international research reputation in the areas of social science research-including education. The research institute in which we were positioned is one of six research institutes supported by the university. The research tnstitute draws its membership primarily from among researchers in the Faculty of Education.

The PDRFs were advertised internationally and the successful applicants were recruited from within Australia, Finland, Singapore, and Trinidad and Tobago. Each PDRF position was aligned with a major body of research being conducted within one of four research groups. These research groups and their leaders were part of the research institute's 
research management structure. The leaders were world class senior Academics. Some research fellows had worked previously in some capacity with at least one of the research leaders, and they were subsequently assigned as our supervisors/mentors.

We four research fellows brought with us extensive research and teaching experience in higher education as well as preestablished connections with education industries in Australia and/or internationally. The first position was loaded at $100 \%$ research, while the other three positions were loaded as $20 \%$ teaching and $80 \%$ research.

\section{The Current Study}

When we started our shared adventure as research fellows, we hoped that working, reflecting, and doing research together would open up new opportunities for understanding our practices [20]. We designed this project within a few days of the last of the four research fellows beginning her position. Our intention was to document and interrogate our experiences, in part as a legacy to any research fellows who came after us, but also as a way of informing the ongoing development of the PDRF within the faculty and contributing to the understandings about PDRF in the broader field of higher education. Our aim was to conduct a study that would illuminate the professional spaces we occupied, by describing the context and analysing any tensions and potential opportunities arising as we interacted with the established professional identities and practices within the institution. The study was informed by Cultural Historical Activity Theory.

4.1. Cultural Historical Activity Theory. Developing out of Vygotsky's sociocultural theory, Cultural Historical Activity Theory (CHAT) is a theoretical framework for exploring human activity [21]. From a CHAT perspective human activity is conceptualised as actions performed by individuals (or groups of individuals) with different subjective positions and histories (subjects), within collective, dynamic, objectoriented systems, which are mediated by social and cultural materials and conditions (artifacts, rules, community of practice, and division of labor), illustrated by Engeström's [22, page 78] triangular diagram (see Figure 1). Mediators, that is, factors that influence activities, form a basic principle of CHAT [23]. They can be concrete tools, but also things that "make interaction possible, such as common language and shared mental models" [23, page 44]. In addition, institutional and social structures act as mediators, often in an implicit manner [24]. If all parts of the system were to be in harmony then the system would be static. However, from a CHAT perspective, because the system is open and historically situated, it is always in tension and open to change. Any changes to one element of the system, for instance, when new participants enter bringing different points of views and interests, can create misalignments, disruptions, and contradictions in the existing system. These tensions can provoke collaborative questioning amongst participants in the activity system and are the driving force for challenges

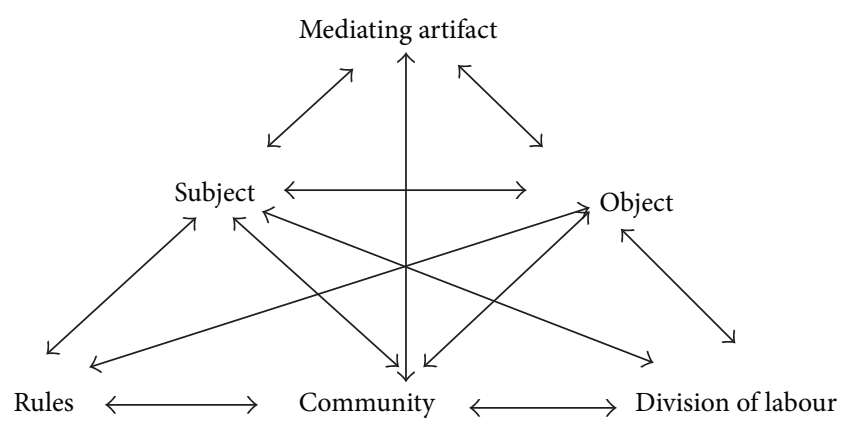

Figure 1: Components of the CHAT system [22, page 87].

to existing practices that can lead to the creation of new ways of working. CHAT has been used widely for developing understandings about practice and supporting learning, in diverse fields including education (e.g., [25]) and teacher education [26].

4.2. Method. Data for this study were gathered from a range of participants using three methods, audio recordings and notes from peer mentoring meetings, individual reflective journals, and interviews with key informants.

4.2.1. Peer-Mentoring Meetings. We established peer-mentoring meetings as safe and secure spaces where we could share resources, ideas, and experiences and support one another [18]. We recognized that these meetings had the potential to yield valuable data to inform the current project and we factored them into our research design from the beginning as places where we would dialogue about (1) how our academic/researcher identity was being constructed and developed, (2) any tensions arising within our dual roles as teacher/researcher and researcher/teacher, and (3) how structures within the university were working to construct our identities as early career researchers.

The discussions were by and large informal collegial gettogethers where we reflected back to our interpretations and sought clarity for our understandings. Because we were based on three geographically distant campuses the meetings were usually executed via Skype. These meetings occurred approximately once a month between November 2010 and March 2012. In addition, we had approximately three faceto-face meetings over the three-year period. We took notes of these meetings and six were audio-recorded (7 hours of recordings in total).

4.2.2. Individual Reflective Journals. Approximately every second month one research fellow prompted us to respond to questions about critical incidents, significant people, emotional issues, and learning, as well as an imagined picture of what a research fellow position should ideally be. The prompts were based on symbolic interactionism, which defines the process of identity building as an active, meaningmaking, and context-related human action [27]. Altogether there were seventeen journal entries covering a ten-month period of time. Rather than concentrating on different levels 
TABLE 1: Example of the first level analysis.

Example of first level analysis

\begin{tabular}{|c|c|}
\hline CHAT element & Example \\
\hline Subject & $\begin{array}{l}\text { A passion for their research area, an inclination towards collaboration, a disposition towards learning, } \\
\text { aspirations about a career I guess and being clear about where they are and where they would like to be. }\end{array}$ \\
\hline Object & $\begin{array}{l}\text { Expected outcomes are that the research productivity of the school, not just the people themselves but the } \\
\text { whole school will be raised by, if you like, this injection of research enthusiasm and capacity in the school. }\end{array}$ \\
\hline Activity & $\begin{array}{l}\text { The demonstrable integration of teaching and research that postdocs are able to demonstrate provides a } \\
\text { very healthy model for the rest of the faculty about how this actually can be done. And the work that they } \\
\text { do in their postdoctoral research contributes to the richness of the teaching inside the faculty. }\end{array}$ \\
\hline Artifact & $\begin{array}{l}\text {...support them in terms of professional development funds and certainly in terms of the culture and } \\
\text { connectedness of the school, they're able to come and participate in any school based activities, so they're } \\
\text { certainly a part of what I encourage them to do and invite them to do, obviously they're able to attend } \\
\text { teaching and learning and research seminars within the school. }\end{array}$ \\
\hline Rules & $\begin{array}{l}\text { I think it's a question of how much autonomy and independence these people can be given. We've said } \\
\text { they're incredible researchers and have remarkable potential. Well then don't let's put sort of constraints on } \\
\text { their geographic location when we know that they can work so well independently without that necessary } \\
\text { kind of minute supervision and be here every day. }\end{array}$ \\
\hline Community of practice & $\begin{array}{l}\text { As a listener I guess that, you can come to me with crazy ideas and ask me about them. And I can say yes } \\
\text { or no, collectively and individually, without sometimes having to have that, supervisory role that you } \\
\text { actually have with your, with the research group leader. }\end{array}$ \\
\hline Division of labor & $\begin{array}{l}\text { I think the general role is about bringing the post doc on as a partner in the work that's being done but } \\
\text { also to stimulate his or her own directions in terms of research. } \\
\text { She is a full member of the team; she has expertise and what we need to do is to develop that expertise and } \\
\text { share what we can do. }\end{array}$ \\
\hline History & $\begin{array}{l}\text { In } 2006 \text { there was a lot of discussion about the need to improve research productivity, the need to grow } \\
\text { research capacity and there was a plan in place that had just been worked through earlier in the year about } \\
\text { possible ways to do that. And one of the thoughts, one of the strategies written into that plan was the } \\
\text { possibility of having Post Docs, and as a way to really boost the capacity of the researchers in the faculty as } \\
\text { a strategy to start doing things differently, to start forming research teams, to really try to work on } \\
\text { building critical mass. }\end{array}$ \\
\hline
\end{tabular}

of reflection, the journal writing aimed to gain a holistic image of our practice [28].

4.2.3. Interviews with Key Informants. Following ethics approval, we conducted interviews with our four supervisors (one of whom was also the Director of the Research Institute which funded the positions) and two Heads of School (HoS) in which we were physically located (two research fellows shared one HoS, and one HoS was unavailable during the interview period). Each interview was conducted by two research fellows (not the research fellow for whom the supervisor or HoS had responsibility). Interviews lasted between 30 and 60 minutes and followed a semistructured format with questions related to the role of the research fellows, the expected outcomes, any challenges and benefits, and their role in supporting the research fellows. The six interviews were audio-recorded and transcribed.

4.3. Data Analysis. Through a CHAT lens, we conceptualized the university institution in which we undertook our PDRF as an object-oriented activity system. The focus of this analysis is on what were the historical, social, material, and cultural practices that shaped our experiences as PDRFs; what disruptions, contradictions, and misalignments occurred as a result of us entering the activity system; and what constructions of the PDRF emerged as a result of the negotiations of these tensions. It is not the intention of this paper to provide an example of how CHAT provides a useful analytical tool to examine educational practice (see, [26] for such a discussion). Rather, CHAT was used as a heuristic framework for analyzing and interrogating the data gathered so as to examine our experiences as PDRFs.

At a first level of analysis, all data were entered into the qualitative data software package NVivo. Using CHAT as a heuristic framework to aid identification of the various historical, social, material, and cultural aspects of our activity as PDRF, phrases, sentences, and paragraphs were coded (by both the second author and a research assistant until consensus was reached). This was done according to the eight key CHAT elements to which the data was most closely related: subjectivities; object; activity; artifact; rules; community of practice; division of labor and history. Likecoded data fragments were then grouped together. Examples of this first level analysis are provided in Table 1.

At a second level of analysis, the categorised data were then interrogated for examples of disruptions, contradictions, and misalignments both within and across the various elements of the activity system; it is the findings from this secondary level analysis that we report here. From this critical 
reflection we identified tensions across four objects, hereafter referred to as "demands" of our positions as PDRFs within the institution. These tensions were mediated by institutional practices and structures as well as personal professional characteristics. We also identified ways that the negotiations of these tensions contributed to new constructions of the PDRF within the institute. To ensure their anonymity, extracts from our supervisors and HoS presented below are not differentiated; instead they are referred to as coming from "interviewees" and in the course of the discussion are not connected to a particular research fellow.

\section{Findings}

Our PDRFs were marked by our negotiation of four competing-though not mutually exclusive-demands related to the institute's research productivity, its research culture, and teaching and to our personal professional goals (the object of the PDRF). These demands were cultural historical products that shaped thinking and feeling at the institute [24]. Below we discuss each of these demands and how we negotiated them and identify factors that either negatively impacted, or which supported and sustained us. As new positions, the PDRFs broke the existing harmony and thus transformed institutional structures.

\subsection{The Demand of Contributing to Research Productivity.} Not surprisingly, given the academic climate of accountability requirements and efficiency [5], our PDRF positions were initiated to directly contribute to the faculty's research productivity. It was expected that, drawing on our doctoral research and/or our international and industry connections, we would develop publications and contribute to external funding proposals. But we were also expected to align our research with and work collaboratively on existing and emerging research programs headed by senior academics, in order to "contribute to, develop and speed up the research program." Some interviewees saw this function as an important mechanism for sustaining the senior researchers. For instance, one interviewee noted

I also think the post docs are very important to the health and well-being of the senior academics in the school because they provide a new way of looking at things and new avenues for creating projects and ideas.

The requirement that we work on existing collaborative projects provided us with valuable opportunities to learn the "rules" of research that Åkerlind [10] notes is an important function of the PDRF. Indeed, in some cases we had opportunities to lead projects. However, our requirement to work on preestablished programs of research somewhat challenged our capacity to develop our own independent research profile. In some instances, we were little more than what one interviewee referred to as "a super research assistant on steroids." Agency is situated in relationships rather than in individuals and needs to be negotiated [29]. Thus our time and space to work independently on our own research was sometimes compromised (see [6]). This danger was recognised by one interviewee who noted

I think it's critical that the post docs don't end up being research assistants or research officers for the established researchers... The established researchers have other ways of getting research assistants if that's what they want.

In order to manage these research demands we each had to engage in constant negotiations with our supervisors about the research we conducted, in ways that met both our interests. Sometimes we acquiesced, other times we resisted the pressure to work on programs of research. Reflecting on these negotiations one interviewee noted

I think each of you is probably arriving at a slightly different crystallisation of how many things you're doing that your mentor has a lower degree of enthusiasm or interest in-versus a higher degree... But these are very delicate human negotiations and I always think that they're best taken slowly and over time and so that you're developing a working relationship with one another.

Some of us found these negotiations particularly challenging, especially, given our relatively junior status, the tenuous nature of our positions and (for three of us) our lack of experience in the Australian research context. The structural relations of power were thus implicitly mediating our relations and possible activities (see [24]).

5.2. The Demand of Contributing to the Development of the Faculty's Research Culture. A second demand of the PDRF was that we would contribute to disrupting the existing research culture within the faculty, which, at that time, similar to many faculties of education [17], was marked by a tradition of emphasis on teaching rather than research. One interviewee told us, for instance, that

The expected outcomes [of the PDRF] are that the research productivity of ... the whole school will be raised by ... this injection of research enthusiasm and capacity in the school.

Thus, as in the words of one interviewee, we were expected to "leave a research footprint," which would not only "guide and support the next lot of Post-Docs" but also provide a lasting legacy "something on which other people can build." This meant that we were assigned a task of transforming the existent practices. There was no standard procedure of being a PDRF and this provided us a good basis for new formations (see [30]).

Through our focus on research, it was envisaged that we would provide a model to junior academics of how to "do" research, "something that they (other faculty members) might aspire to do too." One interviewee summarised that the research fellows are as follows:

the role of making explicit that linkage between theory and practice, research and teaching. They 
[research fellows] contribute to the sense of collaboration within the school about research and they certainly create an ethos and help to build a culture where research is regarded as a highly legitimate part of an academic's workload.

Thus, by having research as a major component of our workload we were to demonstrate the importance of research and publishing for the teacher education community (see [16]).

Our positions constituted a new research profile between the senior and junior faculty academics and we were to be a conduit between these different levels of faculty staff flattening out hierarchies and contributing to a more even division of labor. As one interviewee put it, we were to build

a bridge between the early career researchers, and the world-renowned researchers, to help the world-renowned researchers with their research, but also as a bridge. So that, it was much easier for early career researches to actually start to move forward and through up to that mid-career range.

To form this bridge we undertook a range of activities in the faculty such as supervising Ph.D. degree students; organising seminars and conferences; attending meetings and chairing research committees; inviting and hosting visiting scholars and mentoring colleagues. We provided possibilities for more junior academics to more readily make upward social comparisons, in which a person compares him/herself to a more advanced person [31]. If another person's skills are slightly-but not too much-more advanced, a comparison with him/her can encourage self-enhancement and selfimprovement $[31,32]$. So from the interviewee's perspectives, it was not enough for us to merely be good researchers, we also needed to have the skills, capacities, and dispositions to work in collegial and collaborative ways. As put by one of the interviewees,

[An ideal] Post-Doc would be collaborative ... and almost have a split personality, that is, getting on with their own work, but also buying into the work programs and profile of other people in the school.

Mediating our ability to contribute to the research culture of the faculty, were the skills, dispositions, histories and capacities we each brought with us-our subjective positions. As Daniels [24] indicates, positioning happens in a social context, which frames the practices. So, not surprisingly, given the limited availability of PDRF in field of education [10] and their cost for the institution, we were told by an interviewee that "people are investing a lot of hope in the arrangement." With this came a corresponding fear that this investment could prove wasted if we were unsuccessful. Therefore, it was important that the institution chooses candidates with the characteristics likely to succeed. The interviewees noted that it was important to "pick winners" and that it would have been "a disaster really or a big waste of money to employ the wrong people." When asked about the characteristics they felt were important for research fellows, along with proven research capacity, "talent and ingenuity," interviewees identified a passion for their research area, an inclination towards collaboration, a disposition towards learning, and being engaging, capable, enthusiastic, and committed people.

There was little recognition from the interviewees, however, that we were expected to change culture from positions of limited power, which precluded us from making any structural changes at the institutional level. There was some acknowledgement that our positions, which enabled us to devote ourselves to research, might have been construed as inequitable and/or threatening to others in the faculty. For instance, one interviewee noted that we might have been seen as having been "given a free kick-a free hand to do things that other academics dream of." Ironically, in some ways, perceptions that our positions were privileged might have worked contrary to the positive modeling of an academic that had been envisaged.

Moreover, the expectation that we would change the research culture weighed heavily on us. In our discussions we reflected on how we worked with faculty colleagues. For each of us, our work was underpinned by a personal praxis of kindness and empathy, understanding, and sensitivity. For us, academic life was not just about doing research in the field and writing papers to be published. It was also about caring for the people and world that we worked with, finding time and space to stay true to core principles of education, and not sacrificing them to management and administrative responsibilities. Whether or not we realised these aspirations is for others to say.

5.3. Teaching Demands. A further demand on three of us was our teaching responsibilities. Unlike many PDRF, we had a $20 \%$ teaching component in our profiles. After the appointment of the first PDRF, the teaching requirement was added to ensure the PDRF was embedded within and able to effectively engage in school activities. Indeed, the teaching aspect was considered by some interviewees to be an essential element of the PDRF, both for the institution and the PDRF. For instance, one interviewee valued our presence in the faculty as bringing "vibrancy to our teaching." In particular, they noted that we bought diverse intercultural, international, and industry perspectives, which "adds richness, particularly in our regional university."

In keeping with Rybarczyk et al. [8], several of the interviewees considered our having teaching responsibilities as important for our future careers, to demonstrate to future employers that we had a well-rounded profile "as a credible academic." One interviewee stated, for instance, that

A post doc that hadn't been in academia previously, that had come through an undergrad and then a PhD program, a full research post doc doesn't give them access to teaching experiences to build that capacity then to transition into a full academic work situation... Because another 3 years of research on top of the doctorate is a wonderful privilege but it doesn't set them up 
for the demands of balancing of teaching and research.

Yet none of us entered our PDRFs straight after completing a Ph.D. degree and all of us had had previous teaching experience in higher education. Our personal histories seemed not to have had an influence on the interviewee's emphasis on the need for us to have a space for "practising teaching."

As has been found with ECRs [4], some of us with teaching responsibilities found it extremely challenging to balance our teaching and research. Although admittedly limited, our teaching took far longer than the time that had been allocated for it. This was especially the case for those from overseas who had the additional burden of learning the rules related to teaching in an Australian university, with little knowledge about the larger education system for which we were preparing student teachers. Yet, there was little recognition of this additional challenge to the experience of being a PDRF. One interviewee stated, for instance,

The Postdoc does something that a new lecturer A or B usually can't do so readily. Because a new lecturer A or B is finding their feet with the teaching and the subject preparation.

This comment disregards the fact that just like other ECRs we too had to "find our feet" in teaching in a new university, more so when teaching in a foreign context.

The boundary between teaching and research in academic work is a social construction (see [33]). In order to manage this boundary, we had to carefully quarantine our teaching loads. For instance, we had to constantly remind people of the expectations on us and we often had to refuse to participate in certain nonfellowship (i.e., teaching) related duties. In some ways these negotiations demonstrated to our colleagues that we privileged research and modeled how space could be created for conducting research within the faculty. However, these were delicate negotiations within an education faculty with its strong tradition of teaching and where the institutionalized discourse had defined the discursive space and positioned academics mainly as teachers (see [16, 34]). As Kerosuo [35] has noted elsewhere, our experiences of negotiating boundaries, shifting our professional identities, and articulating new practices was uncomfortable and "challenging" (page 183).

5.4. Personal Professional Demands. Just as those within the institute had hopes of what the PDRFs would bring, we too bought with us certain expectations and personal goals that we might achieve by it. We each recognised the promise and potential that mostly or totally research position had for enhancing our academic career $[6,11]$. We regarded the PDRFs variously as an opportunity to focus on our research, learn new skills, become more scholarly, increase our publication output, and develop lasting relationships. The aim was to consolidate and strengthen our profiles as researchers in order to achieve tenure and/or promotion.

Our supervisors also saw the individual benefits of a PDRF and wanted it to contribute to the success of our careers. For instance, when asked their aspirations for "their" research fellow, one interviewee responded for her to have established herself as an excellent researcher in early childhood so that when she goes to wherever she goes after the postdoc, she is able to stand on her own two feet.

Similarly, another noted that

when her Postdoc comes to an end she should have the CV and the wings to really fly wherever she chooses to be.

Further, just as the university had invested in us, we too invested a lot when taking up these positions. Whilst the PDRFs offered each of us a valuable and exciting opportunity to engage in sustained research, it also required us to take significant professional and personal risks, in common with many other research fellows (see [36]). For instance, one of us had to resign from a secure position in her homeland. Three of the four fellows moved countries, from Singapore, Trinidad and Tobago, and Finland, and, for the fourth research fellow, it involved living away from home for extended periods. Being so distant from our homes added an extra burden on us. For instance, for one of us it meant relocating her entire family from the northern to southern hemisphere. These personal costs [36] were the price she and her family paid for the development of her international career. Each of us had to carefully negotiate these professional/personal matters with our families.

\section{Mediating Factors that Challenged, Supported, and Sustained}

6.1. A Lack of Clarity in the Role. Perhaps one of the most challenging mediating factors at an institutional level was the lack of clarity regarding the purpose of the PDRF. Indeed, one of the driving forces behind this study was our uncertainty about our role and the expectations. Our job description lacked detail. Even our very titles proved confusing:

Because it says doctoral in your title everybody thinks you're a doctoral candidate rather than a Post Doctoral Fellow.

In fact our titles changed midway through our tenure from postdoctoral research fellow to research fellow to reduce the confusion that we were doctoral candidates.

Some confusion about the purpose, scope, and expectations of the PDRF is perhaps only to be expected given the relative "newness" of research fellows in education $[10,14]$ and the fact that there was no previous tradition of PDRFs in this particular institute/faculty. Further, whilst this ambiguity was unsettling to us, it did provide an openness that enabled the position to grow in response to the specificities of the local context. As PDRFs become more commonplace within faculties of education it may be possible to develop realistic and achievable, but also locally contingent expectations for these positions.

There was also a lack of transparency in the outputs and outcomes expected of the positions or how these might be measured, which, according to Åkerlind's [10] previous 
study, is a common feature of research fellowships. In this climate of uncertainty, two of us were fixated on achieving the only target outputs that we had been given: 9 publications in 3 years. We kept lists of our publications and joked about how we constantly counted and recounted this list. In this uncertain and slightly amorphous climate, these targets gave us something tangible and concrete to hold on to. Interestingly, whilst this list keeping could have led to competition between us, it instead remained a self-focused driving force.

6.2. Institutional Procedures and Practices. There were a number of institutional factors that impacted our work. We were supported by recruitment, relocation, orientation, and introduction processes that helped us settle into our new roles. One of the greatest supports at an institutional level that sustained us over the three years, however, was the flexible working conditions under which we worked. In particular, arrangements were made, such as accruing leave/conducting research overseas, so that those from overseas could return home. As one interviewee stated

If we can have a whole school in the Faculty of Education that works remotely, I see no reason why we have to constrain our postdocs to remain in Australia. That kind of presentism I don't think suits anybody. And I think getting the balance right between allowing our postdocs or any member of staff whose family is elsewhere to return home and work from home I think is an important consideration.

These small adjustments to the faculty practices were hugely significant in sustaining us during our tenure.

As has been identified in previous research [10] our supervisors played an important role in our experiences as research fellows, especially in regards to creating the research context in which we worked. One interviewee summarised the role of the supervisor:

to be a bit protective, to ensure that their workload is fair and conforms to the agreements that we had about the distribution of their work, to integrate the postdocs as far as we can into the life of the school, to keep a close eye on their work allocations and to generally ease them into the culture of the school.

The supervisors acted as our mentors, giving us entre into the higher echelons of academia, and as gatekeepers, ensuring we had "enough space to develop as a researcher" and at the same time ensuring that we were "not overwhelmed by group commitments and group involvement."

6.3. PDRF Personal Characteristics. Personal characteristics also impacted our work as PDRFs. Although each of us bought to the PDRF our different histories, experiences, knowledge, understanding, and cultural capital, we were perhaps more alike than different. We are all female and whilst all four of us were ECRs, having been awarded our
Ph.D. degrees a couple of years prior to commencing our PDRFs, none of us were "young" academics in terms of age: two were in their 30 s and two in their 40s. Immediately prior to commencing our appointments, three of us had worked at universities in teaching intensive posts as teacher educators and one in a nongovernment organization with research and evaluation responsibilities. Therefore we all had a great deal of life experience and previous experience of working in academia and industry. As one interviewee noted we each bought "a lot of maturity and experience ... with working with people and universities." These "real life" experiences contributed to our ability to transition into and make the most of our experiences as PDRF.

Another personal factor that had a significant impact on two of us was working in a second language. Not only did this require additional effort and longer preparation time for publications but it also involved struggle as they attempted to make their meanings clear in another language and sometimes did not have the words to express themselves. As Moss [37, page 432] notes, working in a second language in academia is a "draining and difficult experience." Further, whilst the research fellows constructed the burden of making themselves understood as a personal "problem," it points to a bigger issue in academia that needs to be considered during an international PDRF. The growing dominance of English in academia has exclusionary consequences, not only are subtle and nuanced understandings meanings lost in translation, it is colonising and subsuming and has "great potential to increase inequality, reduce diversity and enhance certain power relations" [38, page 433].

6.4. Peer Mentoring. As has been noted elsewhere for ECRs [18] peer mentoring also played a significant role in supporting and sustaining us. Despite our different epistemological backgrounds, we developed warm and collaborative relations and professional regard for one another and found these exchanges mutually beneficial and rewarding. As one interviewee noted, through peer mentoring we created "a culture for one another." This culture supported and sustained us by providing opportunities for sharing and working through challenges and frustrations we faced, seeking clarity and affirmation, and for celebrating our successes and achievements. This collaboration formed a resource for us as individuals, but also for the institution, because together we supported each other in reshaping the academic work (see [30]).

\section{What Emerged?}

For the university and the research institute, our navigation of the opportunities and limitations of the PDRF position has facilitated a legacy (or footprint) of academic relationships and connectivity (as opposed to competition); these were supported and sustained by a practice of peer mentoring. This has become evident in research relationships continuing to live and extend into our current relocations geographically and institutionally. The demand of contributing to the research publication profile of the university has been more than well met. As a collective we have been 
able to achieve publications (books, book chapters, peerreviewed journal articles, conferences papers/presentations, and other) and attracted internal and external research grants. These reflect individual and collective projects and contribute to the university's national and international positioning.

At an individual level, as our PDRF experience within this institution has come to an end, we can now speak to the ways in which the particularities of this experience have enabled immeasurable possibilities for our personal professional trajectories. We entered the PDRF positions with fairly strong identities as teacher/researchers. But during the course of our PDRFs as we negotiated, challenged, and/or reconciled with the system our identities shifted to that of researcher/academic. One of us explained that she felt that she had "turned a corner in (her) academic identity journey" so that she now saw herself "primarily as a researcher."

In addition to building our research and teaching profiles, the PDRF experience also enabled our ability to craft a career development strategy that is built upon the foundations of collaborative research (in teams and large programs of research) internationally and locally. We have extended our preexisting national and international research networks and have been provided with the opportunities to be mentored by senior academics, mentor others, and lead research development. These have occurred across a range of academic arenas: as researchers on grant applications-learning the art of competitive grantsmanship; as principal and co-supervisors for higher degree research students-reading for Honours, Masters and $\mathrm{PhD}$ qualifications; as peers engaged in collaborative research and publication with less experienced academics and, as faculty and school committee chairs. The PDRF experience has served to launch our academic careers.

In contrast to the experiences of many PDRF [13] we have each found on-going employment in academia. Tuija has taken up a position as Professor of Teacher Education in Finland. Sandie and Laurette have taken up permanent positions in the Faculty of Education at the university that provides the institutional backdrop for this study. At the completion of the fellowship position they were seconded to the research institute for three years as Assistant Directors with a $60 \%$ administrative and $40 \%$ research load, responsible for liaising with members of the institute to promote and develop explicit structures and practices of research development. Siew Yin has taken up another contracted PDRF position at another major university in Australia.

By using CHAT as an analytical framework, this paper has presented how the formation and conditions of PDRF practices at the institute were influenced by factors such as changing rules, the community of practice, the ways labor was divided, and the agency of PDRFs [24]. As we negotiated these social and cultural material elements and learnt new ways of working and being an academic within this teacher education community we shaped and were shaped by the institution in ways that were outside of the established organisational practices (see [33]).

\section{Final Reflections}

Similar to findings in other studies (e.g., [6]), our PDRF experiences highlighted a lack of clarity about the role of a research fellow, which we found quite unsettling. In our case the PDRF role clearly extended beyond that of a continued apprenticeship to one of research leadership. Perhaps a lack of clarity is only to be expected given the recent emergence of PDRF in faculties of education. Furthermore, schools of teacher education form specific communities of practice in which academic identities are often shaped by a strong commitment to teaching (see [39]). Whilst this ambiguity suggests a need for the development of clear rationales, role descriptions, and expected outputs, it nevertheless allows a great flexibility in how PDRFs are constructed, albeit with a concomitant requirement that these roles be clearly communicated at a local level. In addition, there is a need to renegotiate the social and cultural materials that are used when reshaping the academic culture in teacher education communities [40].

Our research highlights the significant role subjectivity plays in the PDRF. Each research fellow begins their tenure with different histories, experiences, cultural capital, and expectations as well as different levels of risk [36]. These factors need to be considered and appropriate measures taken by institutions to support the research fellow. Further, whilst some characteristics, such as research capacity, would be universally recognised as necessary for a PDRF, otherssuch as the ability to lead or contribute to organisational change-may be more place-specific and institutions would do well to consider their particular needs and the realities of individual capacities and expectations during the recruitment process.

For each of us, our PDRFs were overwhelmingly positive experiences. They provided us with opportunities not typically available to an ECR within teacher education. In particular, our research intensive positions and access to world class scholars, gave us skills, widened our perspectives and insights into academia, provided opportunities for publishing, and assisted us in the creation of our places in the academic world (see [6]). Yet we did experience some challenges that have been previously reported in the literature. In particular we found it difficult to balance our teaching and research, and the burden of learning about teaching in an Australian university was not necessarily reduced. As a consequence, similar to other ECRs, we would argue that research fellows with teaching responsibilities need institutional support and organisational structures which help to balance these two demands [4].

Amongst the factors that supported us was having access to highly respected scholars with whose work ours closely aligned and who invested time and energy in mentoring and protecting us. Also supportive was the peer mentoring, and we value the fact that our supervisors supported these opportunities and that funding was made available for us to meet regularly. We would recommend that organisational structures such as these be available to all research fellows.

We recognise that this research provides the story of PDRFs in only one institution, that other PDRF experiences 
may differ, and that further research is necessary for a comprehensive examination of the PDRF experience. However, we believe this study provides a useful contribution to the emerging body of literature on the PDRF experience.

\section{Conflict of Interests}

The authors declare that there is no conflict of interests regarding the publication of this paper.

\section{References}

[1] L. Archer, "Younger academics' constructions of "authenticity", "success" and professional identity," Studies in Higher Education, vol. 33, no. 4, pp. 385-403, 2008.

[2] O. Hallonsten and C. Silander, "Commissioning the University of Excellence: Swedish research policy and new public research funding programmes," Quality in Higher Education, vol. 18, no. 3, pp. 367-381, 2012.

[3] Opetusministeriö, Direction and funding of universities as from 2010, Finnish Ministry of Education, Helsinki, Finland, 2009.

[4] B. Hemmings and R. Kay, "Research self-efficacy, publication output, and early career development," International Journal of Educational Management, vol. 24, no. 7, pp. 562-574, 2010.

[5] B. Hemmings and R. Kay, "University lecturer publication output: qualifications, time and confidence count," Journal of Higher Education Policy and Management, vol. 32, no. 2, pp. 185197, 2010.

[6] G. S. Åkerlind, "Postdoctoral researchers: roles, functions and career prospects," Higher Education Research \& Development, vol. 24, no. 1, pp. 21-40, 2005.

[7] E. Mackinlay and K. Barney, "Pearls, not problems: exploring transformative education in Indigenous Australian studies," The Australian Journal of Indigenous Education, vol. 41, no. 1, pp. 1017, 2012.

[8] B. Rybarczyk, L. Lerea, P. K. Lund, D. Whittington, and L. Dykstra, "Postdoctoral training aligned with the academic professoriate," BioScience, vol. 61, no. 9, pp. 699-705, 2011.

[9] M. Ghayur, "Providing a setup and opportunities for better training of postdoctoral research fellows in an academic environment," Journal of Postgraduate Medicine, vol. 54, no. 2, pp. 156-157, 2008.

[10] G. S. Åkerlind, "Postdoctoral research positions as preparation for an academic career," International Journal for Researcher Development, vol. 1, no. 1, pp. 84-96, 2009.

[11] H. Horta, "Holding a post-doctoral position before becoming a faculty member: does it bring benefits for the scholarly enterprise?" Higher Education, vol. 58, no. 5, pp. 689-721, 2009.

[12] ETUCE/CSEE, Teacher Education in Europe. An ETUCE Policy Paper, ETUCE European Trade Union Committee for Education, Brussels, Belgium, 2008.

[13] G. Borlee, "Where do all the postdocs go?," DNA and Cell Biology, vol. 30, no. 8, pp. 537-538, 2011.

[14] M. Hulme and P. Sangster, "Challenges of research(er) development in university schools of education: a Scottish case," Journal of Further and Higher Education, vol. 37, no. 2, pp. 181-200, 2013.

[15] B. E. Lovitts, "The transition to independent research: who makes it, who doesn't, and why," Journal of Higher Education, vol. 79, no. 3, pp. 296-325, 2008.
[16] T. M. Willemse and F. Boei, “Teacher educators' research practices: an explorative study of teacher educators' perceptions on research," Journal of Education for Teaching, vol. 39, no. 4, pp. 354-369, 2013.

[17] B. Levin and Y. He, "Investigating the content and sources of teacher candidates' personal practical theories (PPTs)," Journal of Teacher Education, vol. 59, no. 1, pp. 55-68, 2008.

[18] L. G. Driscoll, K. A. Parkes, G. A. Tilley-Lubbs, J. M. Brill, and V. R. P. Bannister, "Navigating the lonely sea: peer mentoring and collaboration among aspiring women scholars," Mentoring \& Tutoring: Partnership in Learning, vol. 17, no. 1, pp. 5-21, 2009.

[19] F. J. Ayala, "Postdoctoral training: valuable? Satisfactory?" American Scientist, vol. 93, no. 3, p. 194, 2005.

[20] L. Coia and M. Taylor, "Co/autoethnography: exploring our teaching selves collaboratively," in Research Methods for the Selfstudy of Practice, D. L. Tidwell, L. M. Fitzerald, and M. L. Heston, Eds., vol. 9 of Self Study of Teaching and Teacher Education Practices, pp. 3-16, Springer, Dordrecht, The Netherlands, 2009.

[21] Y. Engestr and Y. Engeström, "Expansive learning at work: toward an activity theoretical reconceptualization," Journal of Education and Work, vol. 14, no. 1, pp. 133-156, 2001.

[22] Y. Engeström, Learning by Expanding: An Activity-Theoretical Approach to Developmental Research, Orienta-konsultit, Helsinki, Finland, 1987.

[23] H. Daniels, "An analysis of the introduction of process- optimisation software in a chemical pulp mill," in Activity Theory in Practice. Promoting Learning Across Boundaries and Agencies, A. Edwards, Y. Engestr, T. Gallagher, and S. R. Ludvigsen, Eds., pp. 25-48, Routledge, Abingdon, Va, USA, 2010.

[24] H. Daniels, "Implicit or invisible mediation in the development of interagency work," in Activity Theory in Practice. Promoting Learning across Boundaries and Agencies, A. Edwards, Y. Engestr, T. Gallagher, and S. R. Ludvigsen, Eds., pp. 105-125, Routledge, Abingdon, UK, 2010.

[25] P. Boyd and K. Harris, "Becoming a university lecturer in teacher education: expert school teachers reconstructing their pedagogy and identity," Professional Development in Education, vol. 36, no. 1-2, pp. 9-24, 2010.

[26] R. Wilson, "Examining teacher education through culturalhistorical activity theory," Teacher Education Advancement Network Journal, vol. 6, no. 1, pp. 20-29, 2014.

[27] D. A. Snow, "Interactionism: symbolic," in International Encyclopedia of the Social \& Behavioral Sciences, N. J. Smelser and P. B. Baltes, Eds., pp. 7695-7698, Elsevier Science, Amsterdam, The Netherlands, 2004.

[28] K. Zeichner and D. Liston, Reflective Teaching: An Introduction, Taylor \& Francis, Boca Raton, Fla, USA, 2013.

[29] H. Daniels and A. Edwards, "Introduction," in Activity theory in practice. Promoting learning across boundaries and agencies, H. Daniels, A. Edwards, Y. Engeström, T. Gallagher, and S. R. Ludvigsen, Eds., pp. 1-8, Routledge, Abingdon, UK, 2010.

[30] Y. Engeström, "New forms of learning in co-configuration work," Journal of Workplace Learning, vol. 16, no. 1-2, pp. 11-21, 2004.

[31] R. L. Collins, "For better or worse: the impact of upward social comparison on self- evaluations," Psychological Bulletin, vol. 119, no. 1, pp. 51-69, 1996.

[32] C. Sedikides and A. P. Gregg, "Portraits of self," in The SAGE Handbook of Social Psychology, M. A. Hogg and J. Cooper, Eds., pp. 110-138, Sage, London, UK, 2003. 
[33] A. Edwards and I. Kinti, "Working relationally at organisational boundaries: negotiating expertise and identity," in Activity Theory in Practice. Promoting Learning across Boundaries and Agencies, H. Daniels, A. Edwards, Y. Engeström, T. Gallagher, and S. R. Ludvigsen, Eds., pp. 126-139, Routledge, Abingdon, UK, 2010.

[34] B. Davies and R. Harre, "Positioning: the discursive production of selves," in Discourse Theory and Practice. A Reader, M. Wetherell, S. Taylor, and S. J. Yates, Eds., pp. 261-271, SAGE, London, UK, 2001.

[35] H. Kerosuo, "Boundaries in health care discussions: an activity theoretical approach to the analysis of boundaries," in Managing Boundaries in Organizations: Multiple Perspectives, N. Paulsen and T. Hernes, Eds., pp. 169-187, Palgrave, Basingstoke, UK, 2003.

[36] J. Richardson and J. Zikic, "The darker side of an international academic career," Career Development International, vol. 12, no. 2, pp. 164-186, 2007.

[37] P. Moss, "English as a problem language," Contemporary Issues in Early Childhood, vol. 11, no. 4, pp. 432-434, 2010.

[38] J. Kincheloe and S. Steinberg, "Indigenous knowledges in education: complexities, dangers, and profound benefits," in Handbook of Critical and Indigenous Methodologies, N. K. Denzin, Y. S. Lincoln, and L. T. Smith, Eds., pp. 135-156, Sage, Los Angeles, Calif, USA, 2008.

[39] E. Wenger, Communities of Practice: Learning, Meaning, and Identity, Cambridge University Press, Cambridge, UK, 1998.

[40] W.-M. Roth, K. Tobin, R. Elmesky, C. Carambo, Y. McKnight, and J. Beers, "Re/Making identities in the praxis of urban schooling: a cultural historical perspective," Mind, Culture, and Activity, vol. 11, no. 1, pp. 48-69, 2004. 

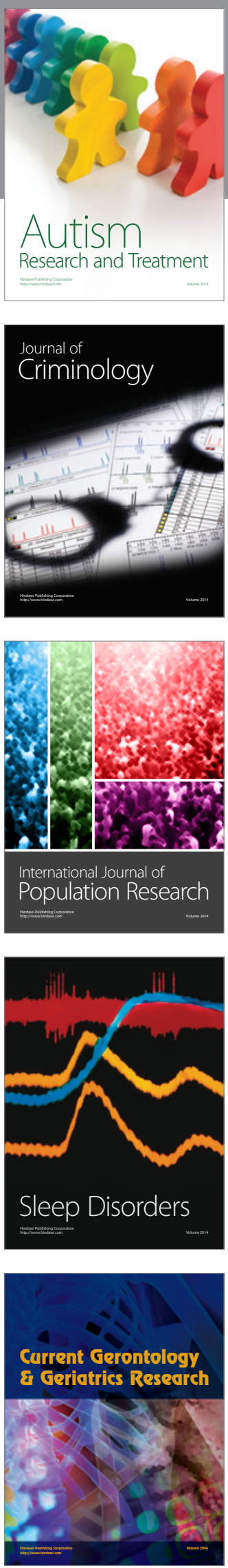
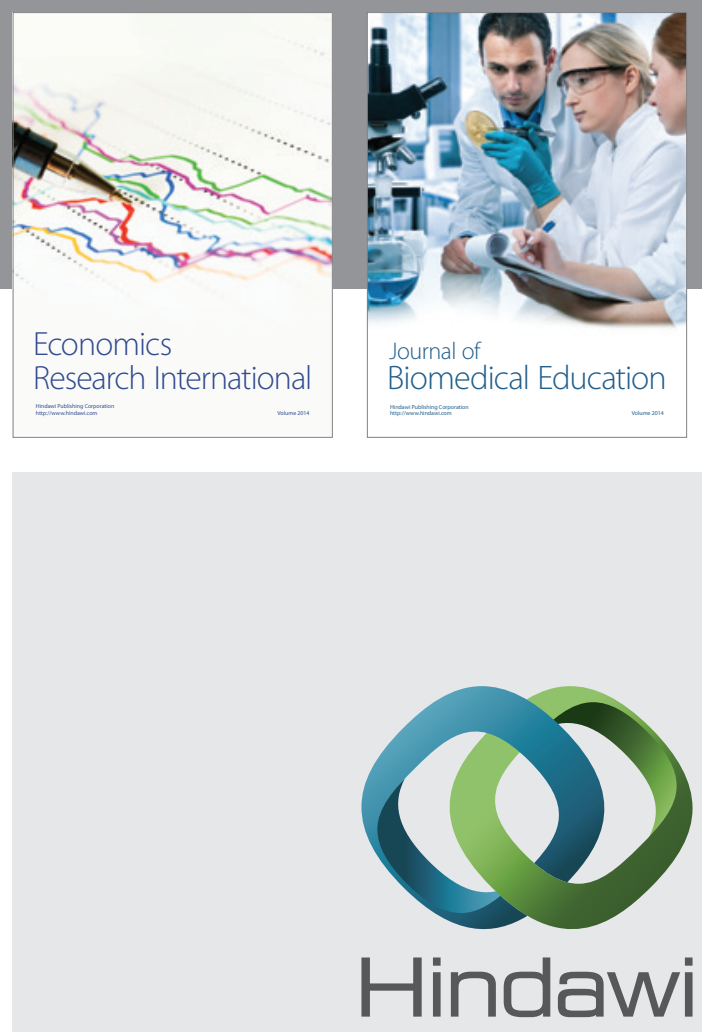

Submit your manuscripts at

http://www.hindawi.com
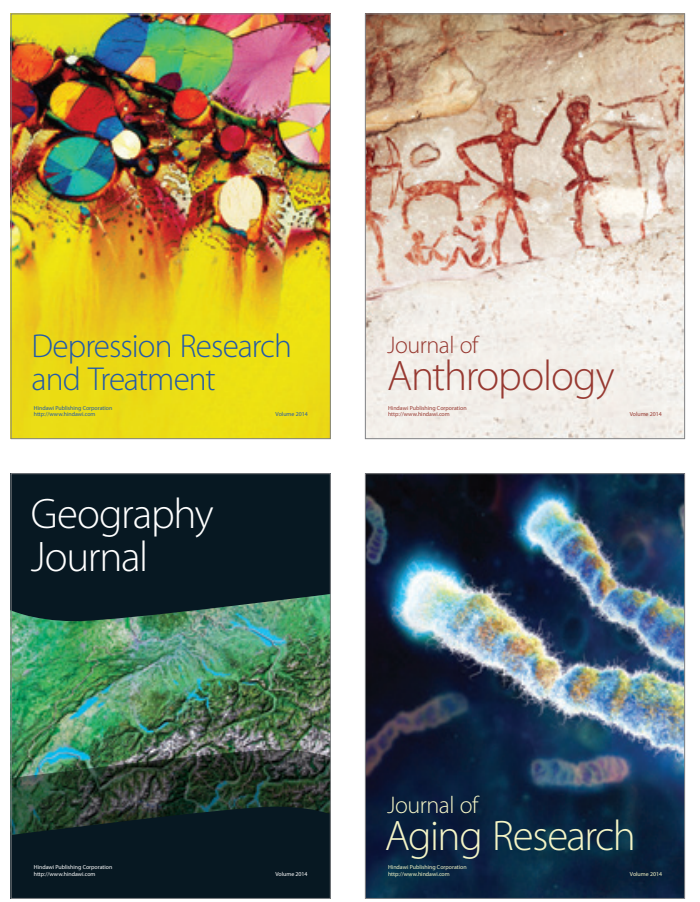
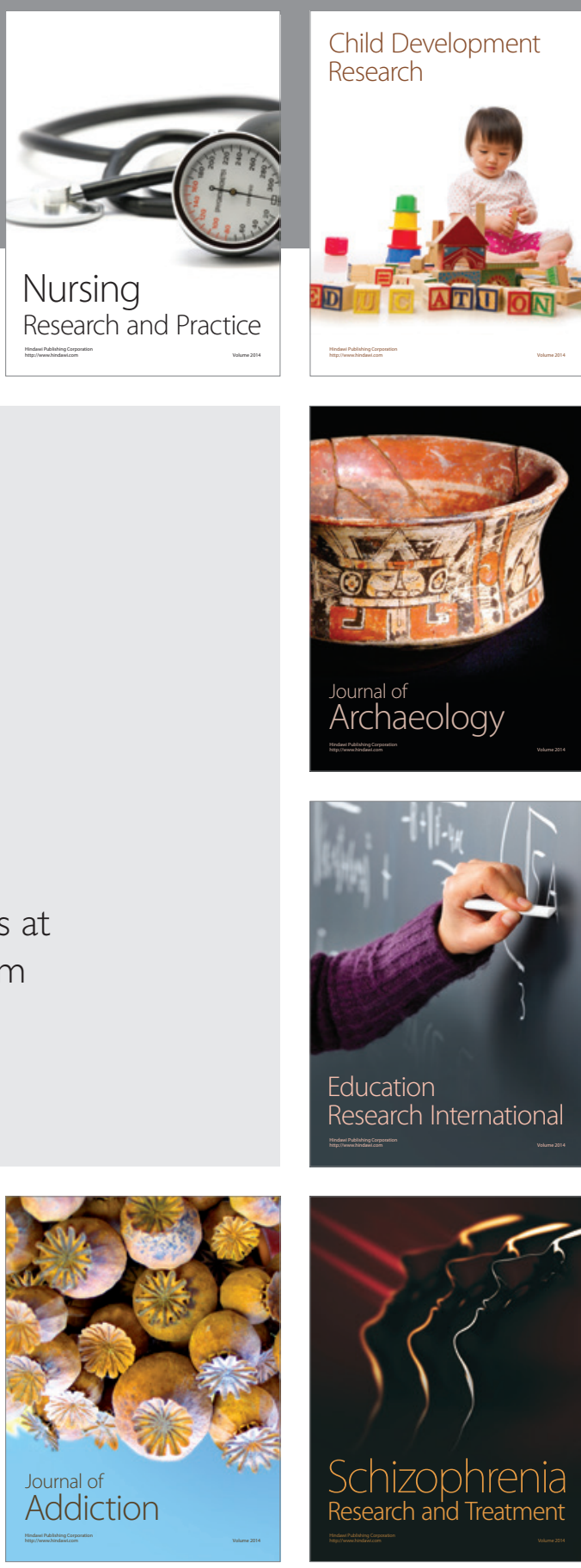

(D)
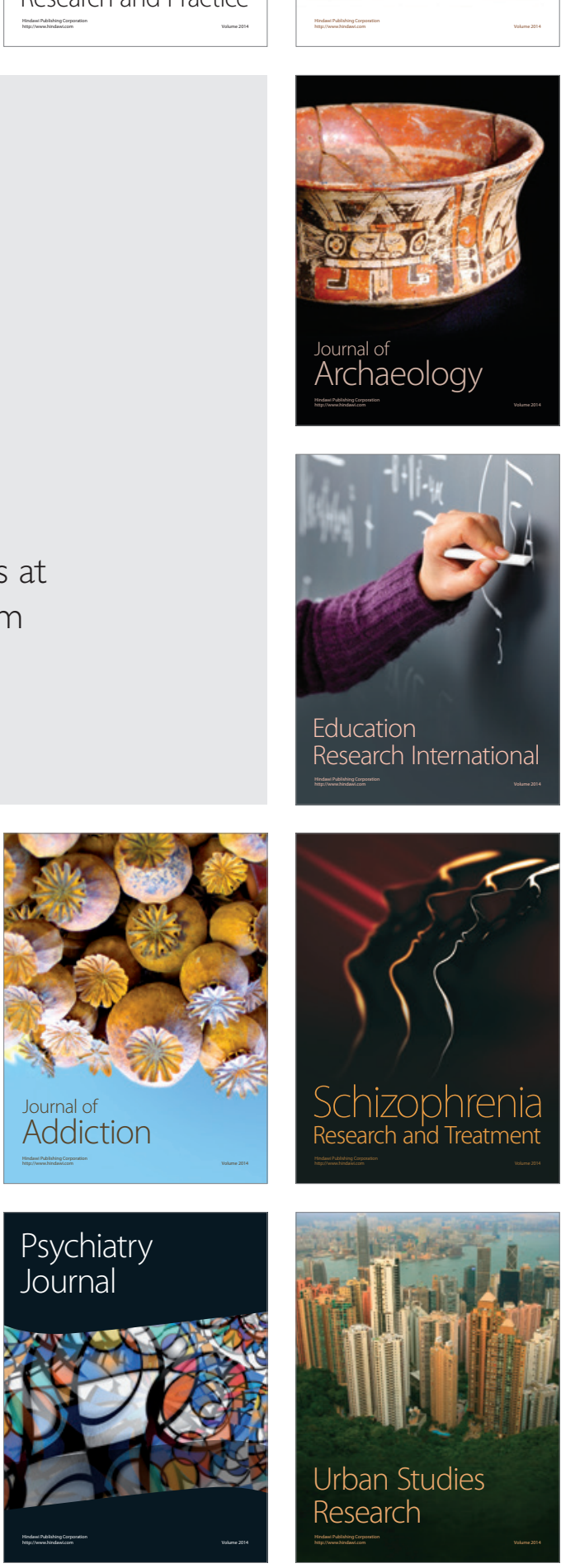